\author{
Pedrós Esteban, Armand-Thierry. \\ Profesor Asociado, Universitat Politècnica de València, Departamento de Escultura, Laboratorio de \\ Creaciones Intermedia.
}

\title{
Construcción de la imagen de una escultura con subproductos pétreos
}

\section{Construction of the image of a sculpture with stony by-products}

\author{
TIPO DE TRABAJO: comunicación \\ PALABRAS CLAVE \\ Escultura, talla de la piedra, subproducto, sostenibilidad, arte.
}

KEY WORDS

Sculpture, sculpting Stone, by-product, sustainability, art.

RESUMEN

Tradicionalmente la talla de la piedra se ha considerado como un proceso sustractivo sujeto a preceptos metodológicos estrictos. En su evolución, a día de hoy, ha tenido una gran importancia la aplicación de la tecnología tanto en materiales como en técnicas automatizadas de trabajo. A nivel de obtención del material base no existen límites. Pero se redunda en la aplicación rígida de las técnicas de tallado. Esto significa dejar aplicar algunas posibilidades a nivel constructivo que la harían evolucionar a nivel conceptual y expresivo.

Queremos conseguir un cambio en la percepción de los volúmenes de la escultura en piedra a través de la combinación de diferentes materiales pétreos con resina de poliéster. Para ello nos valdremos de subproductos de la industria de la piedra como vía sostenible que minimiza el impacto ecológico derivado del modelo de explotación y destrucción del entorno.

Esto va a suponer una modificación del concepto de la talla de la piedra y por tanto de su imagen. La percepción que tendremos de la imagen cambiará nuestra comprensión del proceso de la talla.

Una vez construido nuestro nuevo soporte lo trabajaremos con herramientas y accesorios que integran tanto el diamante (natural y/o sintético) así como el carburo de tungsteno. Estas herramientas y accesorios los utilizaremos combinados con maquinaria eléctrica y/o neumática para dar la forma al conjunto.

Mantendremos un registro de imágenes de trabajo donde se analizará tanto el procedimiento utilizado como el resultado final a nivel visual y conceptual.

Con lo expuesto anteriormente, demostraremos que resulta posible integrar materiales pétreos que nos sirvan de base para realizar esculturas y comprobaremos que las propiedades de estos materiales son idóneas para la talla a todos los niveles. Demostraremos también el cambio en la percepción de la imagen que se genera a partir de la utilización esta técnica y la comprensión global de la técnica de la Talla.

\section{ABSTRACT}

Traditionally, the size of the stone has been considered as a subtractive process subject to strict methodological precepts. In its evolution, to date, the application of technology in both materials and automated work techniques has been of great importance. At the level of obtaining the base material there are no limits. But it results in the rigid application of the carving techniques. This means letting apply some possibilities at a constructive level that would make it evolve at a conceptual and expressive level. 
We want to achieve a change in the perception of the volumes of the sculpture in stone through the combination of different stone materials with polyester resin. For this we will use as byproducts of the stone industry as a sustainable way that minimizes the ecological impact derived from the model of exploitation and destruction of the environment.

This is going to suppose a modification of the concept of the size of the stone and therefore of its image. The perception that we will have of the image will change our understanding of the process of carving.

Once built our new support we will work with tools and accessories that integrate both the diamond (natural and / or synthetic) as well as tungsten carbide. These tools and accessories will be used combined with electrical and / or pneumatic machinery to give shape to the whole.

We will keep a record of working images where both the procedure used and the final result at the visual and conceptual level will be analyzed.

With the above, we will demonstrate that it is possible to integrate stone materials that serve as the basis for sculptures and we will verify that the properties of these materials are ideal for carving at all levels. We will also demonstrate the change in the perception of the image that is generated from the use of this technique and the global understanding of the technique of the Size.

\section{INTRODUCCIÓN}

Aunque inicialmente puede parecer que el contenido de esta comunicación es difícil de englobar en los planteamientos que dirigen este congreso, a lo largo de la exposición demostraremos como lo que vamos a desarrollar afectará tanto en la generación como la concepción de la imagen a nivel escultórico.

Vamos a establecer los contenidos marco sobre los que iniciaremos la exposición y que resultan necesarios para poder comprender el desarrollo de los acontecimientos.

Tenemos que dar por aceptada y ya asimilada la rotura de la figura para encerrar el entorno en su interior (WHITKOWER, 1984). Concepción en la que se trabaja con el espacio como materia (WHITKOWER, 1984). Y en la que tenemos muy presente la afirmación de David Smith que postulaba que "Ia escultura está tan libre como la mente; es tan compleja como la vida".

En esencia, nos vamos a aproximar en parte a la visión de Ülrich Rückriem en la que se aleja tanto de motivos como de técnicas clásicas de la escultura figurativa tradicional para explorar los problemas fundamentales de la escultura: medidas, volumen, material y su relación con el espacio circundante.

Apostamos por la eliminación del concepto del monolito (a la manera tradicional) como aquella materia que contiene o que va a engendrar la escultura. Por contra, nosotros la generaremos teniendo en cuenta nuestras necesidades tanto expresivas como constructivas. La talla la consideraremos como un proceso más. No como proceso asociado inevitablemente a la talla de la piedra.

Queremos desligar de la talla la idea de que únicamente tiene sentido la aplicación del proceso extractivo. Apostamos por la hibridación de los sistemas constructivo/sustractivo según nuestras necesidades. Esto supone dejar de lado la consideración de la talla como simple sistema de reproducción.

Cuando queremos replantear nuestra visión sobre la talla, tenemos que considerar necesariamente la coexistencia de dos realidades que convergen en ella.

La primera es la necesidad de abrir la mente a la evolución que ha protagonizado la escultura en cuanto a planteamientos de concepto y la segunda a la posibilidad de aplicar avances técnicos derivados del desarrollo industrial (PEDRÓs, 2008). La evolución a nivel de concepto debe de dar por superadas consideraciones anteriores en que se lastra su evolución al supeditarla a un dominio técnico. La aplicación de los avances técnicos irá supeditada a la superación de la primera realidad.

La combinación de las dos realidades supone seguir nuestro camino hacia un máximo expresividad que nos facilite el objetivo final. La comunicación de nuestra realidad y expresión de nuestros sentimientos a través de la escultura.

El desarrollo industrial nos lleva a asumir una realidad tecnológica que nos coloca ante un nuevo punto decisivo en el trabajo de la piedra. Ya no es un material duro y complicado. Pierde parte de la dureza que le es propia y pasa a ser un material "plástico" con el que podemos construir nuestro mundo. 


\section{Material base}

Si partimos de la premisa en la que para definir el material base debemos de disponer de un volumen de piedra que pueda albergar aquello que queremos tallar, nos lleva a considerar que prestamos más importancia al material que trabajamos que a la idea que queremos plasmar. Si lo hacemos así, tendremos que adaptar, modificar o hacer nuestra propuesta teniendo de partida una limitación en cuanto a tamaño. Una limitación que va a marcar el posterior desarrollo de nuestro trabajo.

Si seguimos este argumento, el siguiente razonamiento nos llevará a que prestaremos atención a sus propiedades físicas para determinar la posibilidad de realización de nuestro proyecto. Esto quiere decir que entramos en consideraciones técnicas al margen de las expresivas, cuando la escultura es una forma de expresión y no de demostración técnica.

Cuando pasemos a describir o definir la fabricación del material base, entraremos a definir pautas sobre su significación. Entre otras tiene que cumplir nuestras expectativas a nivel constructivo que posteriormente nos resulten beneficiosas a nivel escultórico. Sus propiedades estarán siempre sometidas a su significación y no a la inversa.

Concebir el trabajo de la piedra a partir de la combinación de diferentes materiales nos lleva a plantear la primera cuestión de importancia.

\section{SE ROMPE EL ESQUEMA DE LA TALLA MONOLÍTICA DE LA PIEDRA}

Este concepto resulta de suma importancia ya que su asimilación de forma general y no parcial ${ }^{1}$ nos va a permitir una evolución en la dirección que nos interesa.

Con ello modificaremos la imagen de aquello que vamos a generar y transformaremos consecuentemente su percepción para conseguir una nueva en la que estableceremos nuestras propias jerarquías tanto de a nivel perceptivo como de significado.

Pero... ¿Esta propuesta ha sido llevada a cabo a lo largo de la historia? ¿Y de qué manera?

Vamos a realizar un breve recorrido histórico donde buscaremos propuestas equivalentes sobre las que analizaremos la forma de proceder. Posteriormente extraeremos conclusiones. De esta manera dispondremos de antecedentes a los que hacer referencia para desarrollar nuestra propuesta y ubicarla en una escala temporal.

\section{$\underline{\text { Historia }}$}

Nos podemos remontar hasta la época romana para obtener las primeras referencias en la aparición de la técnica de la combinación de diferentes materiales pétreos en una misma escultura (normalmente en forma de busto).

Pero dejamos transcurrir el tiempo hasta llegar a los siglos S XVI y XVII donde aparecen más ejemplos de esta técnica. Una buena representación la podemos encontrar en el "Museo del Prado".

En la Figura 1, podemos ver uno de ellos. Vemos un busto realizado a partir de la combinación de diferentes tipos de piedra. Cada una de ellas compone un elemento diferente que define la escultura. Cada color y textura del material se coloca estratégicamente para conseguir imitar aquello que representan. Se sigue un esquema en el que el material utilizado debe representar al material al que imita. Se establece una jerarquía mimética. En la Figura 2 tenemos otro ejemplo. En esta ocasión se mimetiza el color de la piedra con el del color de la piel del personaje. Se establece un contraste entre el blanco y el negro como forma ir más allá en el aspecto de la escultura realizada.

Anteriormente comentábamos la necesidad de asimilar de forma genérica y no parcial el esquema de la rotura de la talla monolítica (MATÍA 2016). Lo que hemos comentado en las Figuras 1 y 2 representa la parcialidad a la que hacíamos referencia puesto que, como ya sabemos, las obras que se realizan durante el Renacimiento no se caracterizan precisamente por la combinación de materiales pétreos como premisa que guía la escultura en la piedra. El uso de esta técnica en este tipo de esculturas no es representativo o susceptible de considerar como corriente conceptual del período histórico.

\footnotetext{
${ }^{1}$ Hace referencia al trabajo ocasional en el que realizamos la combinación de diferentes materiales siguiendo más un esquema preciosista identificando un objeto de lujo, excentricidad o curiosidad.
} 


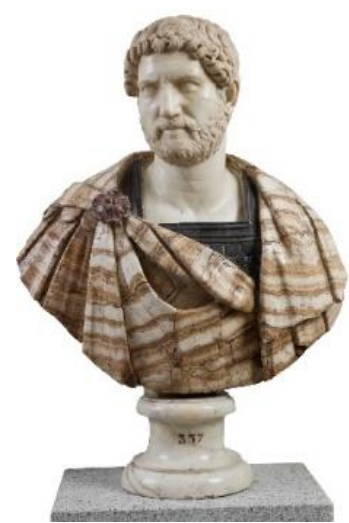

Figura 1. Busto. El emperador Adriano, 1600 - 1650, Anónimo

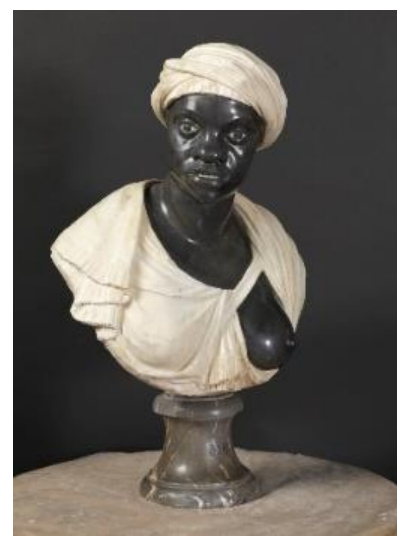

Figura 2. Busto, Una etíope, principios S. XVII. Anónimo

Si sacamos las conclusiones sobre lo que acabamos de analizar, podríamos decir:

1. Este tipo de trabajo se aplica a un soporte figurativo.

2. Se busca un virtuosismo que está más a nivel de la excentricidad y lujo que de una concepción de la escultura.

3. La función de los diferentes tipos de piedra en una misma escultura nos lleva por caminos no sólo de la mímesis con los materiales representados, sino que redunda en planteamientos no significativos en la escultura final (asimilación parcial de la rotura del monolito).

Dicho esto, tendremos que dar un salto de tres siglos para encontrar un referente en el que se utilice la combinación de piedras con la asimilación integra de la rotura o de la talla monolítica de la piedra.

Ya han quedado atrás los planteamientos figurativos y cobrado protagonismo la abstracción. También han quedado asumidos los contenidos marco con los que iniciábamos esta comunicación.

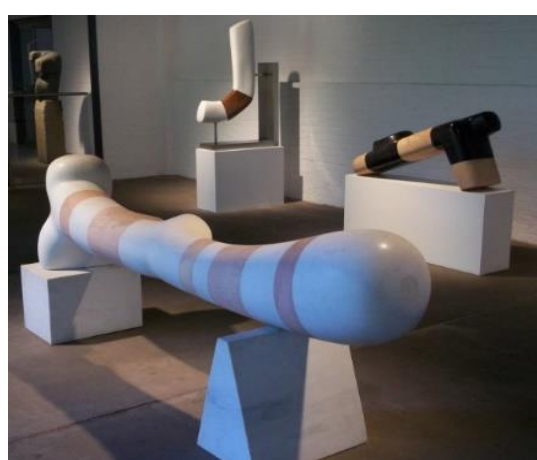

Figura 3. Dig dong Bat, Isamu Noguchi

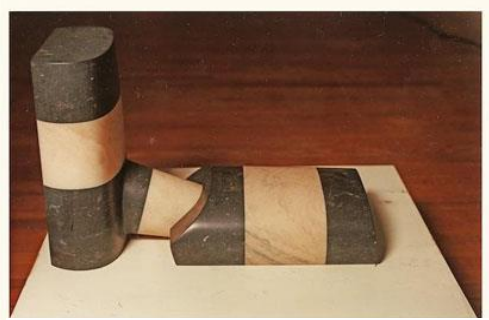

Figura 4. Escultura, To Love, Isamu Noguchi
Tenemos que llegar al S XX y en concreto a la figura de Isamu Noguchi. Llegamos a la combinación de diferentes materiales pétreos para construir las esculturas. En ellas no sólo define el volumen, evidentemente que lo recrea, pero también plasma sensaciones que no le son propias inicialmente. A modo de ejemplo, podemos decir que al observar la Figura 3, distinguimos una direccionalidad que tiende a la verticalidad en una estructura que tiende a la horizontalidad... lo que transforma la percepción de la escultura, y por consiguiente, su imagen.

Asistimos a la nueva construcción de la imagen de la escultura. Podemos hacer una doble lectura ya que la podemos ver tanto íntegra como descompuesta. Podemos analizar la deconstrucción del volumen y la posterior construcción con elementos de diferentes propiedades visuales. En un posterior análisis más profundo sobre la obra de Noguchi, la técnica de unión de diferentes materiales se ha interpretado como la representación, integración y plasmación de su patrimonio japonés-americano. La carga conceptual que se concede a la escultura potencia una imagen y trasciende en una significación más allá de su volumetría.

En la Figura 4, podemos observar la planificación, orden y estudio donde queda definido el lugar de cada uno de los materiales en la escultura. La jerarquía establecida define una simetría de colores y de materiales. Un juego en el que la resultante tiende a un equilibrio y estabilidad. El preciosismo y detallismo asemeja la escultura a un objeto de diseño. Aparece un equilibrio y estabilidad perfectamente planificados.

En el origen de algunas de las esculturas de Noguchi, podemos corroborar que deja de lado el concepto del monolito de la misma manera que la mímesis de materiales de las etapas precedentes. 
Su obra marca un antes y un después en la concepción de la talla de la piedra. Nos resulta el mejor ejemplo como referente para desarrollar nuestra propuesta ya que engloba todo aquello que consideramos necesario para poder conceptualizarla.

Hemos podido considerar que la distribución de los materiales define no solamente volúmenes, sino también sensaciones. Lo dotan de una carga conceptual sin alterar el volumen original. La imagen de las esculturas define un nuevo espacio que rompe la harmonía. La construcción del material base tiene claramente como finalidad la expresividad.

\section{Hibridación del sistema aditivo/sustractivo y sostenibilidad}

Desde el momento en el que contemplamos la realidad de fabricarnos nuestro propio soporte, estamos aceptando la hibridación de los sistemas aditivo/sustractivo. Asimilar este supuesto supone un paso adelante y un cambio conceptual de la talla.

El "nuevo monolito" o material base estará formado por multitud de materiales. Igual que la realidad en la que vivimos, está formada por diferentes fragmentos y su imagen se ve afectada cuando los tenemos presentes.

La planificación de nuestra tarea persigue un modelo productivo en el que vamos a aprovechar recursos ya disponibles para construir nuestra realidad. No queremos partir de un modelo en el que nos limitamos a perpetuar los esquemas de explotación que suponen la depredación del entorno y que tienen como objetivo el máximo beneficio económico posible (SHIVA, MIES 2016). Queremos partir de los recursos ya utilizados puesto que con ello conseguimos básicamente dos cosas: dar forma a nuestro soporte en la escala en la que necesitamos y aprovechar recursos ya disponibles en forma de subproductos minimizando así la generación de residuos y evitando de forma directa la destrucción del entorno.

Estas formas de trabajar nos pueden poner ante una disyuntiva. Dos métodos de trabajo diferentes en el que uno tiene un impacto directo en el contamina y destruye el entorno, y el otro en el que tiene lugar una contaminación por elementos químicos.

Por un lado, seguir el modelo de explotación minera en el que se obtienen bloques de piedra como consecuencia de la degradación y destrucción del entorno. Supone un impacto ecológico tremendo. Un impacto ambiental en el que se destruye y desaparece el patrimonio natural, se generan residuos (aceites, líquidos hidráulicos, maquinaria obsoleta, etc) se utilizan grandes cantidades de combustibles fósiles para alimentar las máquinas que trabajan en las explotaciones, y otros muchos tipos de residuos que afectan el entorno.

Y por otro la fabricación de resinas de poliéster supone también un impacto en el medio ambiente puesto que es una actividad industrial en la que se generan una serie de subproductos que hay que tratar adecuadamente. De no hacerlo correctamente estamos perjudicando el medio ambiente con un tipo de contaminación no tan visible como el esquema anterior pero igualmente perjudicial... ¿Cuál de las dos actividades produce un impacto menor y por tanto resulta más adecuada? ¿Cuál de las dos posibilidades está más cercana al planteamiento de un trabajo en el que minimizamos el impacto sobre el medio ambiente?

Esta discusión puede presentar dudas de muchos tipos. Después de documentarnos nos podemos decantar por la segunda de las posibilidades ya que la fabricación de resinas de poliéster presenta un menor impacto al ser un único proceso químico claro y definido con sus controles perfectamente estipulados por ley. Mientras que en la extracción de piedra en la industria minera lleva asociados diferentes procesos que en conjunto generan un mayor grado de contaminación (aparte de una destrucción irreversible del medio ambiente).

Pero centrándonos de nuevo en el tema de la comunicación vamos a describir la rutina que nos permitirá conseguir nuestro monolito "ecológicamente sostenible". El resultado nos posibilitará conseguir nuestro objetivo. Obtener una escultura con la que comunicaremos nuestros pensamientos, sensaciones y reflexiones más íntimas.

\section{METODOLOGÍA}

Conseguiremos la construcción de nuestro soporte gracias a la utilización de materiales como las resinas de poliéster, el diamante (artificial y natural) y el carburo de tungsteno presentes tanto en herramientas como en accesorios. Estos materiales nos abren unas posibilidades, que, si somos capaces de aprovechar, revertirán en una nueva expresividad que cambiará la imagen de la talla de la piedra.

El adhesivo que vamos a utilizar presenta el formato de masilla. Es una resina tixotrópica de poliéster con efecto anti descolgante y de gran viscosidad. Aplicaremos con ella una carga de pigmento. Sus propiedades mecánicas permiten seguir el mismo proceso que con la piedra natural, y como podemos apreciar en las imágenes, juega un papel determinante. La unión resulta rápida, sencilla y definitiva. 
La cohesión de los diferentes elementos es absoluta y su resistencia, en la mayor parte de las ocasiones, está por encima de la dureza de los elementos unidos. El resultado final lo conseguiremos visualizar durante el mecanizado su mecanizado

La metodología de trabajo que seguiremos se centra en el encolado de diferentes fragmentos de piedra, en forma de subproductos, hasta conseguir el formato que nos permita llevar a cabo la talla.

Iniciaremos el proceso preparando las superficies que encolaremos ya que los subproductos que utilizamos poseen una de sus caras tratadas para el pulimento y que dificultan el encolado.

\section{DESARROLLO}

Como hipótesis de trabajo vamos a plantear las siguientes:

1. Demostrar que resulta posible integrar materiales pétreos que nos sirvan de base para realizar esculturas

2. Comprobar que las propiedades de estos materiales son idóneas para la talla a todos los niveles.

3. Cambio en la percepción de la imagen de la escultura.

Seguidamente vamos a describir el proceso reconstructivo de la piedra que acabamos de definir con el primer objetivo.

Utilizaremos los subproductos que podemos observar en la Figura 5. El conjunto se compone de calizas y mármoles². Siguiendo un esquema aditivo construiremos el soporte al que posteriormente daremos forma (Figura 6).

Como hemos comentado en ocasiones anteriores, si construimos este soporte, la talla deja de estar sometida al volumen de piedra disponible. Su construcción dependerá de nuestras únicamente de las necesidades según nuestro criterio estético.

En este caso, a diferencia del sistema seguido por Noguchi, la ubicación de cada uno de los fragmentos lo realizamos de forma aleatoria ${ }^{3}$. Nos centraremos en una única pauta según la cual no uniremos dos fragmentos del mismo material. Vamos a buscar la contraposición de colores y texturas mediante el contraste entre materiales maximizado por la utilización de una resina con una carga de pigmento rojo buscando un efecto cromático intenso (KAPOOR, 2010). Como podemos apreciar en la Figura 6 encolaremos los diferentes materiales hasta conseguir las dimensiones iniciales que necesitaremos para continuar con la reconstrucción del volumen.

El peso o carga visual que tiene el volumen (Figuras 6 y 7) no se corresponden con el que tendría si el mismo volumen estuviera integrado por un solo material. La imagen generada queda definida por consideraciones visuales diferentes.

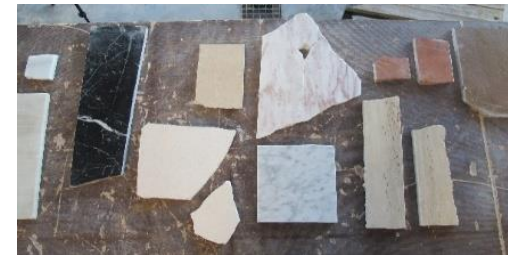

Figura 5. Subproductos pétreos

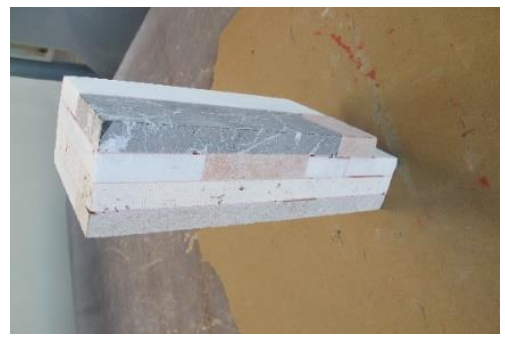

Figura 6. Soporte inicial reconstruido

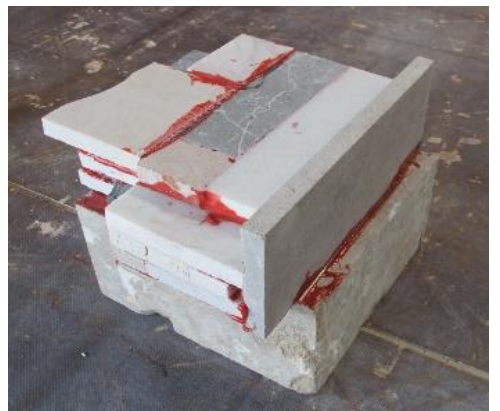

Figura 7. Aspecto inicial del bloque reconstruido

Con esta sistema de construcción podemos centrarnos en aspectos relacionados con la significación y no con consideraciones técnicas. El resultado final vendrá marcado por el dinamismo que toma como base la combinación de diferentes tipos de piedra. Su percepción contará con el color y la textura como fundamento. Esto nos ayudará a definir la escultura. Su imagen dependerá de la jerarquía de materiales que nosotros establezcamos.

\footnotetext{
${ }^{2}$ Los materiales que vamos a utilizar son: calizas como el negro Markina, travertino romano, marfil crema, emperador claro y rojo Alicante. Mármoles como el blanco de Carrara, blanco Macael, mármol de Borriol y rosa potugués.

${ }^{3}$ El sistema seguido por Noguchi planificaba la ubicación de los diferentes tipos de piedra en la escultura. Buscando un equilibrio al contraponer materiales.
} 
Cuando trabajamos sobre un soporte integrado por un único material como la piedra natural, queda anulado como tal ya que visualmente se asimila con rapidez y sirve únicamente para definir el volumen que contiene. En nuestro caso, por el contrario, conseguimos una riqueza de matices que potencian aquello que vamos a tallar.
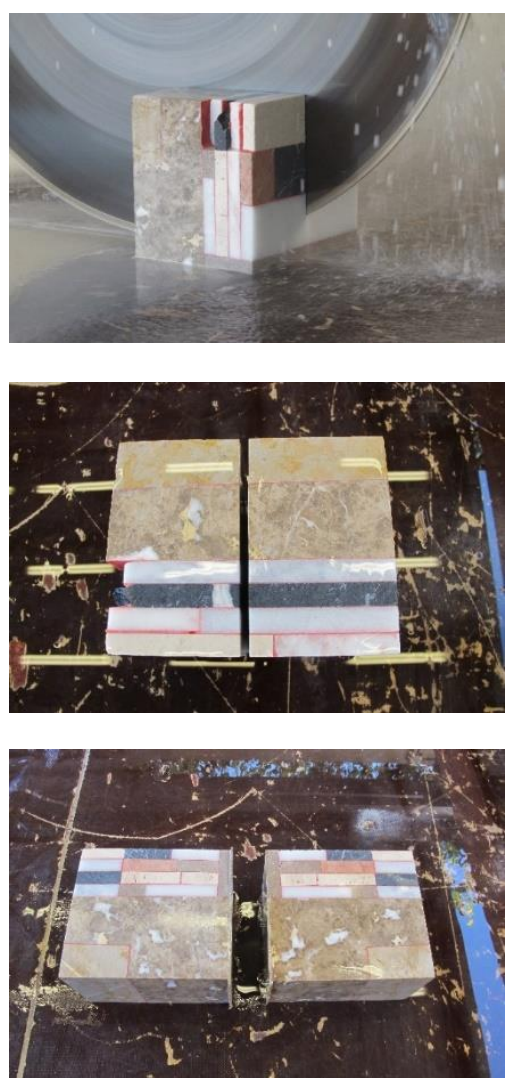

Figura 8. Corte del bloque reconstruido

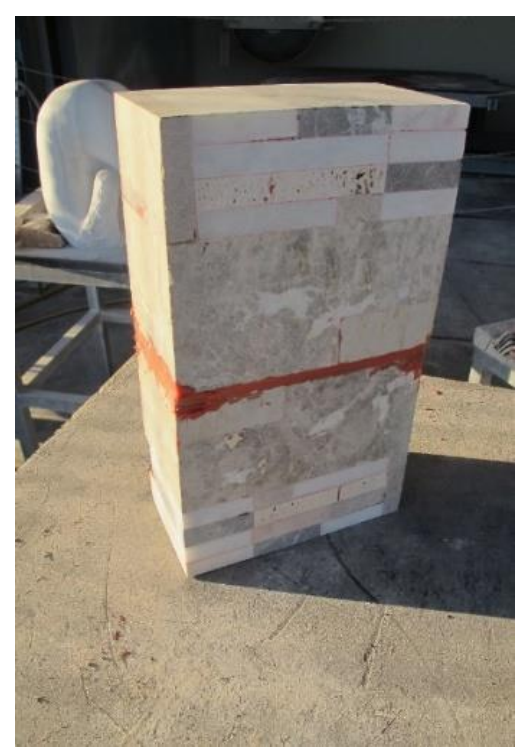

Figura 9. Formato definitivo para realizar la talla
En el conjunto de imágenes que forma la Figura 8 y la 9, podemos apreciar el resultado visual del proceso de integración.

Este bloque nos puede sugerir diferentes posibilidades creativas relacionadas con la ubicación de los diferentes subproductos. Cuando analizamos las imágenes, podemos ver que cada uno de los cortes supone la multiplicación de las franjas de colores y texturas. Una vez encolados multiplicamos su presencia, y dependiendo de la posición que adjudiquemos a cada una de las partes, el resultado final puede variar radicalmente. Posee una riqueza visual diferente al mismo volumen de piedra natural. Cada uno de estos fragmentos podría funcionar como materia prima para nuestras esculturas. Pero una vez unidos de nuevo integran otro volumen diferente. Con ello conseguimos variar la imagen del material base.

Problemas que afecten a la integridad o compacidad de la piedra no nos supondrá obstáculo alguno que nos haga abandonar el soporte por defectuoso. Tampoco los problemas con la dimensión del volumen. Estos problemas y otros que nos puedan aparecer lo resolveremos con rapidez al poderlo redimensionar.

En la Figura 9, después de la reconstrucción a partir de los cortes del bloque de la figura 8, hemos conseguido cambiar de formato sin hacerlo de soporte, y lo más importante, podremos seguir trabajando en nuestra talla sin alterar el planteamiento inicial. Hemos conseguido el material "plástico" al que hacíamos referencia.

En la Figura 10 podemos observar el inicio de la talla. Esta fase se conoce como desbaste. Su correcta ejecución pasa por disponer de un soporte con las condiciones mecánicas adecuadas que lo permitan. En este momento es en el que utilizaremos tanto las herramientas eléctricas y neumáticas con los accesorios a los que hacíamos referencia en el apartado de metodología. Estos integran materiales como el carburo de tungsteno y el diamante natural y artificial.
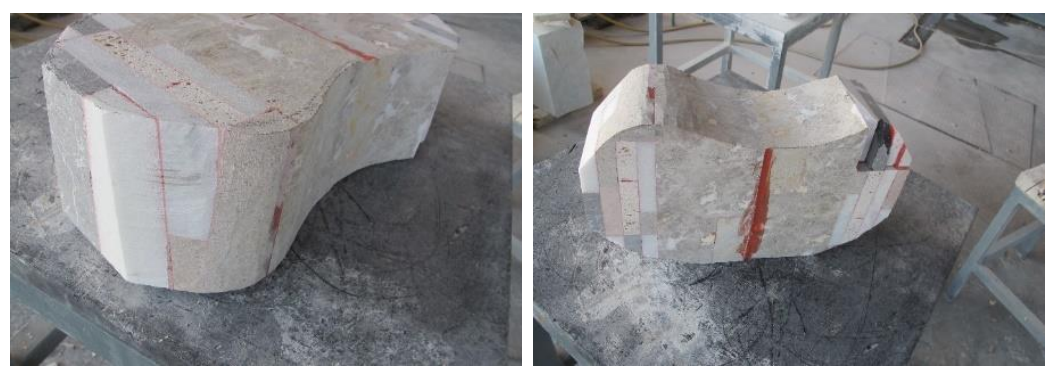

Figura 10. Inicio de la talla del bloque reconstruido

Tanto en la realización de cortes con los discos diamantados como en la aplicación de las herramientas neumáticas que trabajan por percusión, el comportamiento del material reconstruido a partir de subproductos pétreos ha variado mínimamente con el que presenta con la piedra natural. En las posteriores operaciones de rebajado, lijado y pulido ha presentado igualmente un comportamiento idéntico.

La integridad del soporte es máxima y su compacidad responde a nuestras necesidades. En las Imágenes posteriores (Figuras 13, 14, 15, 16, 17) podremos ver la conclusión del proceso de la talla y culminación con la obtención de una escultura con este nuevo material como soporte. 


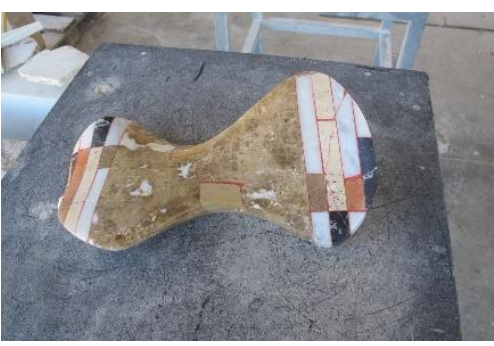

Figura 11. Vista general 1 de la talla

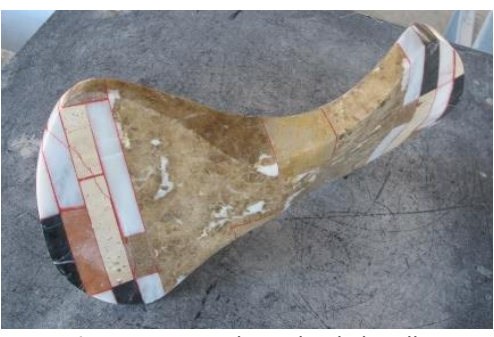

Figura 14. Vista lateral 2 de la talla

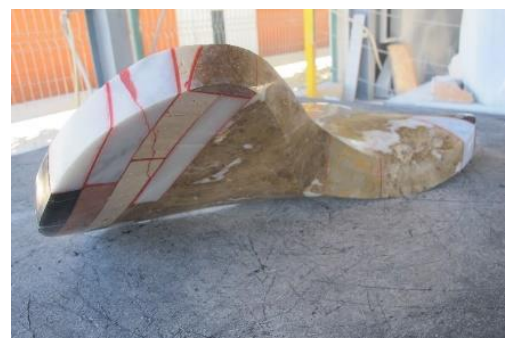

Figura 12. Vista general 2 de la talla

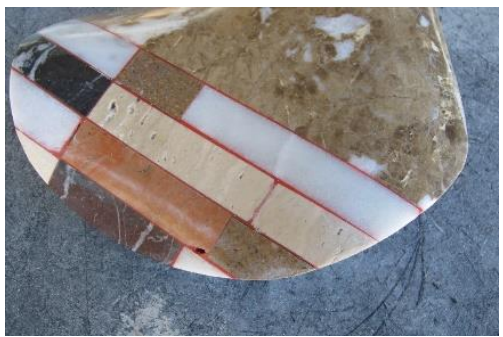

Figura 15. Detalle 1 de la reconstrucción con subproductos

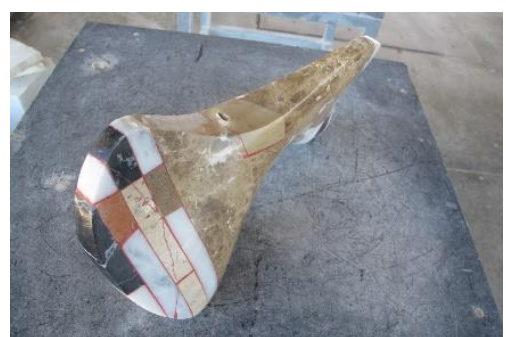

Figura 13. Vista lateral 1 de la talla

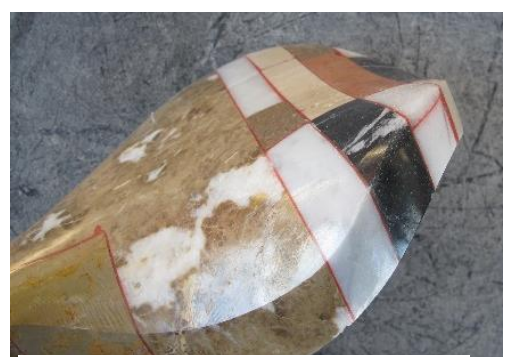

Figura 16. Detalle 2 de la reconstrucción con subproductos

\section{CONCLUSIONES}

Como conclusiones a las hipótesis que habíamos planteado, podemos decir:

a) En cuanto a la demostración de si resulta posible integrar materiales pétreos que nos sirvan de base para realizar esculturas:

Podemos concluir que queda demostrado que resulta posible integrar materiales pétreos en un solo volumen, así como la forma de hacerlo. Para ello hemos trabajado con subproductos pétreos que hemos unido con masilla de poliéster. En la Figura 11 podemos observar el resultado. Tenemos un bloque de piedra reconstruida que utilizaremos como base para nuestra talla.

b) En cuanto a la corroboración de que las propiedades de este nuevo material que hemos conseguido resultan idóneas a todos los niveles para realizar nuestros trabajos:

Podemos concluir que las propiedades de este material resultan ser las idóneas para realizar nuestros trabajos. Como demostración podemos observar las imágenes de las Figuras 11, 12, 13, 14, 15 y 16. En ellas aparece una escultura realizada exclusivamente para confirmarlo.

Como apartado final podemos aportar la última conclusión que podemos corroborar:

c)

La percepción de la imagen de la escultura.

La imagen que generada a partir del trabajo de este material, trasluce matices y contiene consideraciones que van más allá de lo que resulta alcanzable con la piedra natural. La plasmación de sensaciones diferentes, y a veces contrapuestas, origina un diálogo de base con la expresividad que podemos volcar en el soporte.

\section{FUENTES REFERENCIALES}

Kapoor, A. (2010). Catálogo de la exposición organizada por la Royal Academy of Arts, Londre, y el Museo Guggenheim Bilbao. Madrid: Editorial Turner.

Matía, P., Blanch, E.; de la Cuadra, C., de Arriba, P., de las Casas, J. y Gutiérrez, J. L. (2016). Conceptos fundamentales del lenguaje escultórico. Madrid: Editorial Akal.

Mies, M. y Shiva, V. (2016). Ecofeminismo. España: Icaria Editorial. 
Pedrós, A. T. (2008). Glossari escultòric: termes realcionats amb el treball de la cerámica el ferro i la pedra. Mallorca: Editorial Documenta Balear.

Withertower, R. (1984). La escultura. Procesos y principios. Madrid: Alianza editorial.

\section{IMÁGENES}

\section{- Figura 1:}

Busto, El emperador Adriano, 1600 - 1650, Anónimo. Tallado, $95 \mathrm{~cm}$ x $70 \mathrm{~cm}$ x $28 \mathrm{~cm}$. Mármol, Museo del Prado, Colección Real. Número de catálogo E000357. Licencia uso en ámbito académico, investigación, estudio privado o para la circulación interna dentro de una organización educativa reglada (como una escuela, instituto o universidad)

\section{- $\quad$ Figura 2:}

Busto, Una etíope, principios S. XVII. Anónimo, Tallado, $77 \mathrm{~cm}$ x $55 \mathrm{~cm}$ x $23 \mathrm{~cm}$, Mármol de Italia y caliza negra. Museo del Prado Mármol, Colección Real. Número de catálogo E000339. Licencia uso en ámbito académico, investigación, estudio privado o para la circulación interna dentro de una organización educativa reglada (como una escuela, instituto o universidad)

$\bullet$

Figura 3:

Escultura, Dig dong bat, 1968-1969, Isamu Noguchi. Tallado, escultura $59.1 \mathrm{~cm}$ x 23,5 cm x $41.3 \mathrm{~cm}$, Base $35.6 \mathrm{~cm} \times 34.9 \mathrm{~cm} \times 48.9 \mathrm{~cm}$, Base $45.7 \mathrm{~cm}$ x $34.9 \mathrm{~cm} \times 48.9 \mathrm{~cm}$. White statuary marble, pink Portuguese marble, Photo by Gail, (C) The Isamu Noguchi Foundation and Garden Museum, NY

\section{-}

Figura 4:

Escultura, To Love, 1970-1971, Isamu Noguchi. Tallado, 37,8 cm x 28,3 cm x 56,8 cm, Portugese Rose Aurora marble, black Austrian Porticoi marble, C The Isamu Noguchi Foundation and Garden Museum, NY.

- Figura 5:

Fotografía del autor. Subproductos pétreos

- Figura 6:

Fotografía del autor. Soporte inicial reconstruido

- $\quad$ Figura 7

Fotografía del autor. Aspecto inicial del bloque reconstruido

- $\quad$ Figura 8

Fotografía del autor. Corte del bloque reconstruido

- $\quad$ Figura 9

Fotografía del autor. Formato definitivo para realizar la talla

- $\quad$ Figura 10

Fotografía del autor. Inicio de la talla del bloque reconstruido

- $\quad$ Figura 11

Fotografía del autor. Vista general 1 de la talla

- $\quad$ Figura 12

Fotografía del autor. Vista general 2 de la talla

- $\quad$ Figura 13

Fotografía del autor. Vista lateral 1 de la talla

- $\quad$ Figura 14

Fotografía del autor. Vista lateral 2 de la talla

- $\quad$ Figura 15

Fotografía del autor. Detalle 1 de la reconstrucción con subproductos

- $\quad$ Figura 16

Fotografía del autor. Detalle 2 de la reconstrucción con subproductos 